\title{
Methionine supply alters mammary gland antioxidant gene networks via phosphorylation of nuclear factor erythroid 2-like 2 (NFE2L2) protein in dairy cows during the periparturient period
}

\author{
L. Han, ${ }^{* 1}$ F. Batistel,$\dagger^{1}$ Y. Ma, $\ddagger$ A. S. M. Alharthi, $\dagger$ C. Parys, $\S$ and J. J. Loor $\dagger^{2}$ \\ *Department of Animal Science and Veterinary Medicine, Henan Agricultural University, Zhengzhou, 450002, China \\ †Department of Animal Sciences and Division of Nutritional Sciences, University of Illinois, Urbana 61801 \\ łInstitute of Animal Nutrition and Feed, Inner Mongolia Academy of Agriculture and Animal Husbandry Sciences, Hohhot 010031, P. R. China \\ $\S$ Evonik Nutrition and Care GmbH, Hanau-Wolfgang, 63457, Germany
}

\begin{abstract}
The periparturient period is the most critical period during the lactation cycle of dairy cows and is characterized by increased oxidative stress status. The objective of this experiment was to evaluate the effect of supplementing rumen-protected methionine on nuclear factor erythroid 2-like 2 (NFE2L2, formerly NRF2) protein and target gene expression in the mammary gland during the early postpartal period. Multiparous Holstein cows were used in a block design experiment with 30 cows per treatment. Treatments consisting of a basal control diet (control) or the basal diet plus rumen-protected methionine (methionine) were fed from $\mathrm{d}-28$ to 60 relative to parturition. Mammary tissue biopsies were harvested on d 21 postpartum from 5 cows per treatment. Compared with control, methionine increased dry matter intake, milk yield, and milk protein content. Among plasma parameters measured, methionine led to greater methionine and lower reactive oxygen metabolites. Compared with control, methionine supply resulted in greater mRNA abundance of the NFE2L2 target genes glutamate-cysteine ligase catalytic subunit $(G C L C)$, glutamate-cysteine ligase modifier subunit ( $G C L M)$, glutathione reductase (GSR), glutathione peroxidase 1 (GPX1), malic enzyme 1 (ME1), ferrochelatase (FECH), ferritin heavy chain 1 (FTH1), and $\mathrm{NAD}(\mathrm{P}) \mathrm{H}$ quinone dehydrogenase 1 (NQO1) in the mammary tissue. In addition, methionine upregulated the mRNA abundance of NFE2L2, NFKB1, MAPK14 and downregulated KEAP1. The ratio of phosphorylated NFE2L2 to total NFE2L2 protein, and total heme oxygenase 1 (HMOX1) protein
\end{abstract}

\footnotetext{
Received November 27, 2017.

Accepted May 3, 2018.

${ }^{1}$ These authors contributed equally.

${ }^{2}$ Corresponding author: jloor@illinois.edu
}

were markedly greater in response to methionine supply. In contrast, total protein abundance of Kelch-like ECH-associated protein 1 (KEAP1), which sequesters NFE2L2 in the cytosol and reduces its activity, was lower with methionine. Besides the consistent positive effect of methionine supply on systemic inflammation and oxidative stress status, the present data indicate a positive effect also on antioxidant mechanisms within the mammary gland, which are regulated, at least in part, via phosphorylation of NFE2L2 and its target genes. The exact mechanisms for these responses merit further study.

Key words: antioxidant response, lactation, oxidative stress

\section{INTRODUCTION}

Oxidative stress is associated with dairy cattle health and milk production during the periparturient period (Roche et al., 2013; Osorio et al., 2014b). During the perinatal period, the primary challenge experienced by dairy cows is a sudden state of negative energy and AA balance coupled with increased nutrient requirements for milk production (Drackley, 1999). This period of intense metabolic activity leads to a greater production of reactive oxygen metabolites (ROM) and increases the susceptibility of dairy cows to disease (Roche et al., 2013; Osorio et al., 2014b; Sordillo and Aitken, 2009).

Methionine is one of the major limiting AA in lactating dairy cows (Schwab and Broderick, 2017), and it can be used in the synthesis of glutathione (GSH) and taurine, 2 of the main intracellular antioxidants (Martinov et al., 2010). Previous research demonstrated that rumen-protected methionine (RPM) supply improved health status and production performance in dairy cows (Chen et al., 2011; Osorio et al., 2013; Zhou et al., 2016a; Batistel et al., 2017). At least in the liver, evidence indicates that RPM elicits positive effects on oxidative stress and inflammation partly through alter- 
ations in mRNA abundance (Naeem et al., 2012; Osorio et al., 2014a; Zhou et al., 2016a). Whether antioxidant mechanisms in the mammary gland also are responsive to RPM is unknown. However, the consistent increase in milk protein synthesis suggests that methionine supply has a potential biological impact within mammary tissue.

One of the key intrinsic cellular systems that protects against deleterious effects of ROM or xenobiotic compounds is regulated by nuclear factor, erythroid 2-like 2 (NFE2L2, formerly NRF2; Bryan et al., 2013). In cultured mammary epithelial cells, several antioxidants activate NFE2L2, triggering an increase in the transcription of antioxidant genes (Jin et al., 2016a,b). In an in vivo study, flax meal supplementation increased NFE2L2 mRNA expression in mammary tissue, indicating that NFE2L2 participates in the control of the cellular antioxidant response (Schogor et al., 2013). Thus, these data suggest that NFE2L2, as a transcription factor, plays a key role in regulating mammary cell antioxidant mRNA abundance.

We hypothesized that besides benefitting the systemic inflammatory and oxidative stress status and production performance, greater methionine supply would also be associated with changes in mammary antioxidant mRNA abundance that reflect a protective mechanism against oxidative damage driven by phosphorylation of NFE2L2. Thus, the specific objectives of the present study were to evaluate the effect of methionine supply on phosphorylation of NFE2L2 and mRNA abundance of target genes in mammary tissue.

\section{MATERIALS AND METHODS}

\section{Experimental Design and Treatments}

The Institutional Animal Care and Use Committee at University of Illinois (Urbana; protocol \#14270) approved all the experimental procedures. Details of the experimental design have been reported previously (Batistel et al., 2017). Briefly, multiparous Holstein cows were used in a randomized, complete, balanced block design experiment with 30 cows per treatment. Treatments consisting of a basal control (control) diet with no added methionine or the basal diet plus ethylcellulose RPM (methionine; Mepron, Evonik Nutrition and Care GmbH, Hanau-Wolfgang, Germany) and were fed from d -28 to 60 relative to parturition. Mepron was fed at a rate of $0.09 \%$ and $0.10 \%$ of DMI during the prepartum and postpartum periods, respectively, to achieve a lysine:methionine ratio of $2.8: 1$. This ratio has demonstrated benefits in terms of animal performance and health (Osorio et al., 2013; Zhuang et al., 2014;
Zhou et al., 2016c). During the preliminary period (from -45 to -29 d relative to the expected parturition day), all cows received the same diet with no added methionine. Treatment diets were mixed daily in a tumble-mixer and fed once daily $(1300 \mathrm{~h})$. The ingredients and chemical composition of the diets were reported previously (Batistel et al., 2017). Rations were formulated to meet predicted requirements for minerals and vitamins according to the NRC (2001).

\section{Milk Samples}

Milk yield was recorded daily, and consecutive morning, noon, and evening milk samples were collected weekly (Batistel et al., 2017). Milk samples were stored with preservative at $4^{\circ} \mathrm{C}$ before analysis of fat, protein, and lactose by mid-infrared procedures (Dairy Lab Services, Dubuque, IA).

\section{Plasma Parameters}

Blood samples were collected from the coccygeal vein before feeding using evacuated tubes containing lithium heparin (Batistel et al., 2017). Plasma was obtained by centrifugation at $2,000 \times g$ for $30 \mathrm{~min}$ at $4^{\circ} \mathrm{C}$ and frozen $\left(-80^{\circ} \mathrm{C}\right)$ until further analysis. Methionine and taurine in plasma were analyzed by Evonik Nutrition and Care GmbH (AOAC International, 1995). Reactive oxygen metabolites in plasma were analyzed with the d-ROMs-test (cod. MC002) purchased from Diacron (Grosseto, Italy). Total antioxidant capacity of blood was assessed as ferric-reducing antioxidant power (Benzie and Strain, 1996).

\section{Mammary Gland Samples}

Mammary gland tissue was harvested on d 21 from a subset of 5 cows in each treatment via percutaneous biopsy. The procedure was conducted under mild general anesthesia with Xylazine and local anesthesia with lidocaine $\mathrm{HCl}$. A $3-\mathrm{cm}$ incision was made through the skin and subcutaneous tissue, and then separated from the mammary capsule at the incision site. Approximately $150 \mathrm{mg}$ of tissue was removed using a biopsy needle (Bard Magnum, 12 gauge $\times 16 \mathrm{~cm} ;$ C. R. Bard Inc., Murray Hill, NJ) and immediately snap-frozen in liquid $\mathrm{N}$ and stored at $-80^{\circ} \mathrm{C}$ until later analysis. Pressure was applied for $10 \mathrm{~min}$ to the incision area with sterile gauze to prevent excessive bleeding. The skin incision was then closed with $11 \mathrm{~mm}$ Michel clips and antimicrobial ointment applied to the incision site. Clots resulting from the biopsies were removed by hand at each milking over the following $3 \mathrm{~d}$. 
Table 1. mRNA abundance of nuclear factor erythroid 2-like 2 (NFE2L2), target genes, and other regulators in mammary gland tissue at 21 $\mathrm{d}$ postpartum in cows fed a basal control diet or the basal diet plus ethyl-cellulose rumen-protected methionine from -28 through $21 \mathrm{~d}$ around parturition

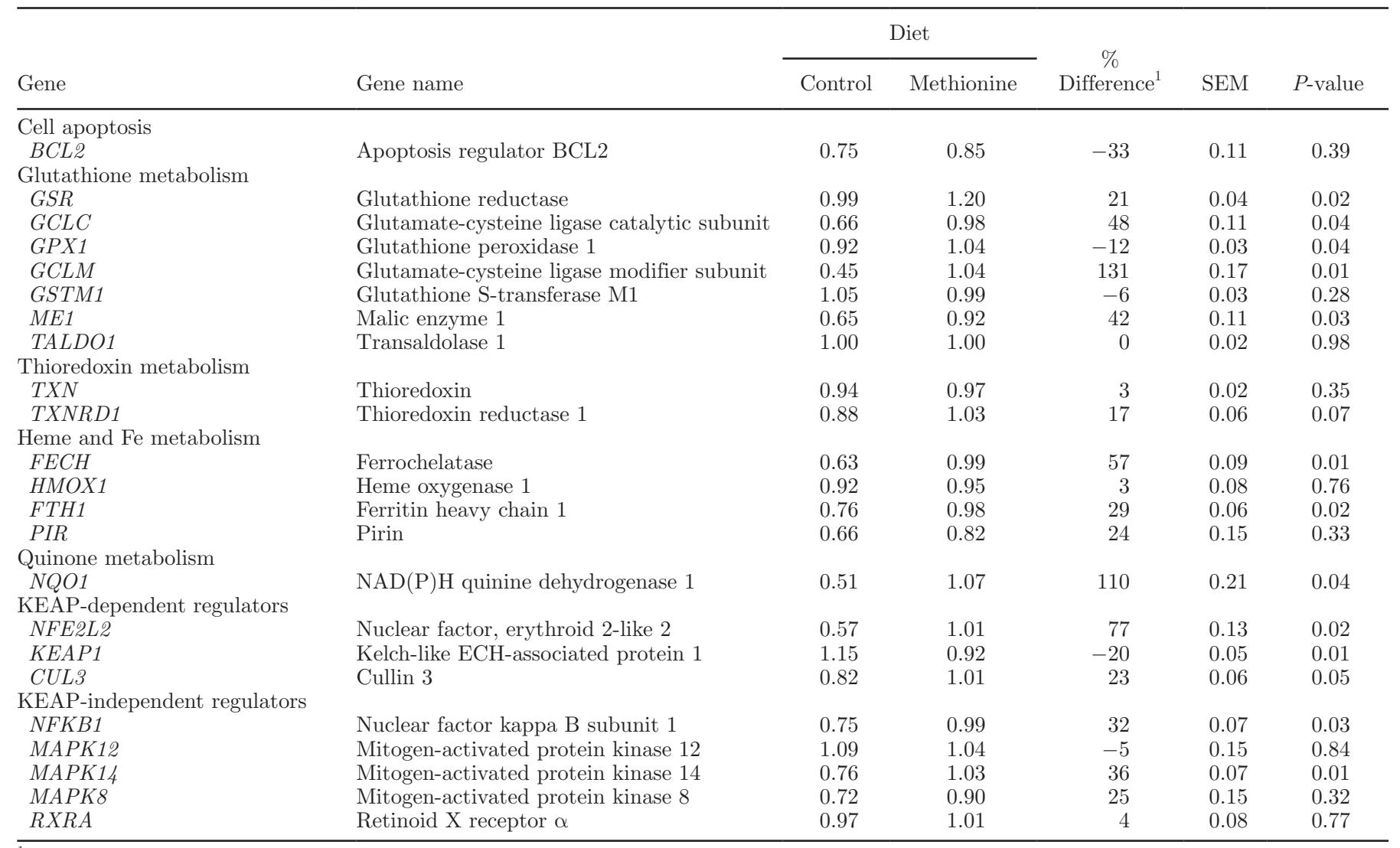

${ }^{1}$ Difference in mRNA abundance $=($ methionine - control $) /$ control $\times 100$.

\section{RNA Isolation, cDNA Synthesis, and Quantitative PCR}

Total RNA was isolated from $50 \mathrm{mg}$ of mammary gland tissue using the miRNeasy kit (Qiagen, Hilden, Germany) according to the manufacturer's protocols. The RNA samples were digested with DNaseI and quantification was accessed using a NanoDrop ND-1000 spectrophotometer (Thermo Fisher Scientific, Waltham, MA). The quality of RNA samples was measured using an Agilent 2100 Bioanalyzer (Agilent Technologies, Santa Clara, CA), and all samples had an RNA integrity number factor greater than 7.3. The quantitative PCR was performed as described previously (Osorio et al., 2014a). The RPS9, RPS15, and $U X T$ were selected as the internal control genes to normalize mRNA abundance data (Bionaz and Loor, 2007). A comprehensive literature search (Chorley et al., 2012; Niture and Jaiswal, 2012; Jin et al., 2016a) was conducted to select NFE2L2 target genes and regulators that play key roles in cellular antioxidant mechanisms. Gene symbols and names are presented in Table 1. Quantitative PCR performance and primer information are included in Supplemental Table S1 (https://doi.org/10.3168/jds.2017-14206).

\section{Western Blot Analysis}

Protein was extracted from mammary gland tissue (50 mg) using a tissue protein extraction reagent (cata$\log$ no. 78510, Thermo Fisher Scientific) containing inhibitor cocktail $(100 \times$, catalog no. 78442; Thermo Fisher Scientific; Xu et al., 2017). Protein concentration was measured using the BCA Assay Kit (catalog no. 23227; Thermo Fisher Scientific). Fifty micrograms of total protein per lane was loaded on a $10 \%$ SDSPAGE and ran at $120 \mathrm{~V}$ for $120 \mathrm{~min}$. Electrotransfer to polyvinylidene difluoride membranes (\#162-0261, Bio-Rad, Hercules, CA) was performed in the TransBlot SD Semi-Dry Electrophoretic Transfer Cell (\#170-3940, Bio-Rad). Membranes were blocked in Tris-buffered saline (TBST) containing 5\% nonfat milk for $2 \mathrm{~h}$ at room temperature. The membranes were then incubated in TBST containing primary antibodies 
to NFE2L2 (catalog no.137550, Abcam, Cambridge, UK), Phospho-NFE2L2 (Ser40, catalog no. PA5-67520, Invitrogen, Carlsbad, CA), KEAP1 (catalog no. 8047, Cell Signaling Technology, Danvers, MA), HMOX1 (catalog no. 70081, Cell Signaling Technology), and GPX1 (catalog no. ARP41491, Aviva Systems Biology, San Diego, CA) overnight at $4^{\circ} \mathrm{C}$. Subsequently, the membranes were washed 5 times with TBST and incubated with horseradish peroxidase-conjugated secondary antibodies (catalog no. ab6721, Abcam) for 1 $\mathrm{h}$ at room temperature. The membranes were washed with TBST and then incubated with Clarity Western ECL Substrate (catalog no. 170-5060, Bio-Rad), and GAPDH (catalog no. ab22555, Abcam) was used as the internal control. Images were obtained with the ChemiDOC MP instrument (Bio-Rad). The intensities of the bands were measured with Image-Pro Plus 6.0 software (Media Cybernetics, Rockville, MD; Supplemental Figure S1, https://doi.org/10.3168/jds.2017-14206).

\section{Statistical Analysis}

The data were analyzed using the MIXED procedure of SAS v.9.4 (SAS Institute Inc., Cary, NC) according to the following model:

$$
\mathrm{Y}_{\mathrm{ij}}=\mu+\mathrm{b}_{\mathrm{i}}+\mathrm{M}_{\mathrm{j}}+\mathrm{e}_{\mathrm{ij}} \text {, }
$$

where $Y_{\mathrm{ij}}=$ dependent, continuous variable, $\mu$ = overall mean, $b_{i}=$ random effect of block, $M_{j}=$ fixed effect of treatment $(\mathrm{j}=$ control vs. methionine $)$, and $\mathrm{e}_{\mathrm{ij}}=$ residual error. Normality of the residuals was checked with normal probability and box plots and homogeneity of variances with plots of residuals versus predicted values. Significance was determined at $P<0.05$.

\section{RESULTS}

\section{NFE2L2 and Target Gene mRNA Abundance}

Compared with control, methionine supplementation resulted in greater mRNA abundance of NFE2L2 target genes including $G C L C(P=0.04), G C L M(P=0.01)$, GPX1 $(P=0.04), G S R(P=0.02), M E 1(P=0.03)$, FECH $(P=0.01)$, FTH1 $(P=0.02)$, and NQO1 $(P$ $=0.04)$. Other NFE2L2 target genes (HMOX1, TXN, GSTM1, TALDO1, BCL2, and PIR) were not affected by methionine (Table 1 ).

Compared with control, expression of NFE2L2 ( $P$ $=0.02), C U L 3(P=0.05), N F K B 1(P=0.03)$, and MAPK14 $(P=0.01)$ was upregulated in response to methionine supply, whereas KEAP1 abundance was downregulated $(P=0.01)$. Other regulators $(M A P K 8$, $M A P K 12$, and $R X R A)$ were not affected by methionine supply (Table 1).

\section{Lactation Performance}

Methionine supplementation led to greater DMI $(+1.7 \mathrm{~kg} / \mathrm{d} ; P=0.01)$, milk yield $(+3.5 \mathrm{~kg} / \mathrm{d} ; P<$ $0.01)$, and milk protein content $(+0.12 \% ; P=0.02)$ during the first $21 \mathrm{~d}$ postpartum (Table 2). No differences $(P>0.10)$ between treatments were observed for milk fat and lactose, or SCC (Table 2). A time effect $(P<0.01)$ during the first $21 \mathrm{~d}$ postpartum was observed for milk yield, $\%$ milk protein, $\%$ milk fat, $\%$ milk lactose, SCC, and DMI.

\section{Plasma Biomarkers}

Compared with control, methionine cows tended to have lower $(P=0.08)$ concentration of ROM and

Table 2. Effects of ethyl-cellulose rumen-protected methionine supplementation to multiparous Holstein dairy cows from -28 through $21 \mathrm{~d}$ around parturition on lactation performance and selected blood biomarkers

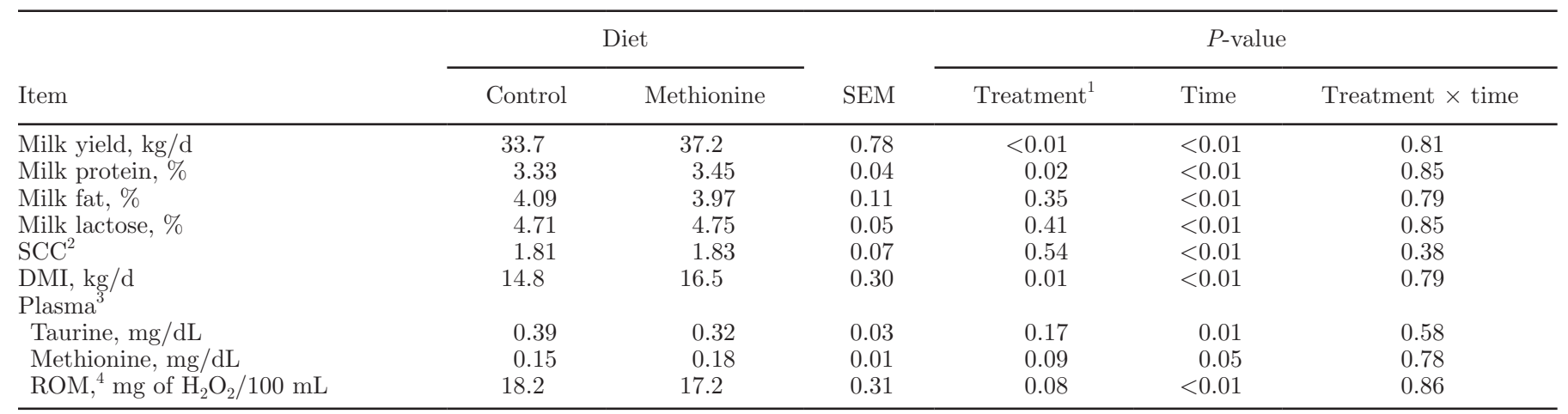

\footnotetext{
${ }^{1}$ Methionine effect.

${ }^{2}$ Data were log-transformed.

${ }^{3}$ Data from d 7 and 21 .

${ }^{4}$ Reactive oxygen metabolites.
} 
Table 3. Expression of proteins (relative units) involved in the nuclear factor erythroid 2-like 2 (NFE2L2) pathway in mammary gland tissue from cows fed a basal control diet or the basal diet plus ethyl-cellulose rumen-protected methionine from -28 through $21 \mathrm{~d}$ around parturition

\begin{tabular}{|c|c|c|c|c|}
\hline \multirow[b]{2}{*}{ Protein $^{1}$} & \multicolumn{2}{|c|}{ Diet } & \multirow[b]{2}{*}{ SEM } & \multirow[b]{2}{*}{$P$-value } \\
\hline & Control & Methionine & & \\
\hline NFE2L2 & 0.92 & 0.45 & 0.08 & $<0.01$ \\
\hline p-NFE2L2 & 1.35 & 1.30 & 0.15 & 0.32 \\
\hline Ratio NFE2L2/p-NFE2L2 & 1.46 & 2.88 & 0.35 & $<0.01$ \\
\hline KEAP1 & 0.98 & 0.79 & 0.11 & 0.02 \\
\hline HMOX1 & 0.35 & 0.55 & 0.09 & $<0.01$ \\
\hline GPX1 & 0.29 & 0.30 & 0.10 & 0.27 \\
\hline
\end{tabular}

${ }^{1}$ p-NFE2L2 = phosphorylated NFE2L2; KEAP1 = total Kelch-like ECH-associated protein 1; HMOX1 = total heme oxygenase 1 ; and GPX1 = total glutathione peroxidase 1 .

higher $(P=0.09)$ concentration of methionine in the plasma. No differences $(P>0.10)$ between groups were observed for taurine concentrations (Table 2). A time effect $(P<0.05)$ was observed for the concentration of taurine, methionine, and ROM.

\section{Protein Expression}

Western blot analysis revealed that total NFE2L2 protein expression was lower $(P<0.01)$, whereas the p-NRF2/NRF2 ratio was greater $(P<0.01)$ in response to increasing the methionine supply (Table 3 ). Methionine supply led to lower $(P=0.02)$ KEAP1 and greater $(P<0.01)$ HMOX1. Abundance of GPX1 was not affected $(P=0.27)$ by methionine supply.

\section{DISCUSSION}

In vitro studies with bovine mammary cells revealed that enhancing methionine supply protects against thermal damage by increasing intracellular antioxidant (Mu et al., 2014; Han et al., 2015). Whether methionine elicits similar effects in vivo is unknown. The present study revealed for the first time that enhancing methionine supply via RPM feeding can upregulate the mRNA abundance of antioxidant genes in part through the phosphorylation of NFE2L2 protein. The potential benefit of methionine on the mammary antioxidant response is likely part of the overall benefits observed on lactation performance and alleviation of inflammation and oxidative stress status in the same group of cows.

\section{Lactation Performance and Plasma Biomarkers}

The beneficial effects of enhancing the supply of methionine during the periparturient period on production performance have been associated with a reduction in inflammation and oxidative stress status (Osorio et al., 2013; Zhou et al., 2016d). The better performance
(DMI, milk yield, and milk protein content) and lower concentration of ROM detected in the subset of cows used in the present study confirm previous data (Batistel et al., 2017, 2018) indicating a reduced oxidative stress status. The greater plasma methionine concentration also agrees with previous research supplementing RPM (Ordway et al., 2009; Zhou et al., 2016b). Therefore, the greater plasma circulating levels of methionine in the methionine cows coupled with greater milk protein content, GSH, and taurine concentrations suggest that a portion of this AA was metabolized to generate these potent antioxidants (Martinov et al., 2010).

\section{NFE2L2-Target Gene Abundance}

Glutathione metabolism via the disulfide reductase systems in the cell involves the transfer of electrons from reduced to oxidized molecules (Berndt et al., 2007). The enzymes GCLC and GCLM are rate-limiting of GSH biosynthesis. The enzyme GSR uses NADPH to reduce GSSG into GSH, and GPX1 uses GSH to neutralize harmful peroxides and ROM (Lu, 2013). The cytosolic enzyme ME1 catalyzes the oxidative decarboxylation of malate to convert $\mathrm{NADP}^{+}$to $\mathrm{NADPH}$ (Ratledge, 2014). Concentration of GSH in periparturient liver is increased in response to enhanced methionine supply (Osorio et al., 2014b; Zhou et al., 2017; Batistel et al., 2018). In bovine mammary cells under thermal stress, methionine supply significantly increased GPX enzymatic activity (Han et al., 2015). Thus, the upregulation of GSH metabolism genes (GCLC, GCLM, GSR, GPX1, and ME1) in mammary tissue of methionine cows suggests that this AA plays a role in attenuating oxidative stress by regulating GSH metabolism in mammary cells.

The reaction of hydrogen peroxide (Fenton reaction) to produce ROM can lead to damage of cellular molecules with important biologic roles (proteins, lipids, and DNA). Considering the potential harmful effects 
of high concentrations of free iron, the cells transport, acquire, and store it by using a dedicated group of proteins (Jansova et al., 2014) including ferritin (FTH1; an iron storage protein) and ferrochelatase (FECH; converts $\mathrm{Fe}^{2+}$ to heme; Gozzelino and Soares, 2014). In human endothelial cells, methionine induces an increase in FTH and suppresses the formation of free radicals (Erdmann et al., 2005). Thus, we speculate that the observed upregulation of FTH1 and FECH abundance are indicative of a protective effect of methionine supply from iron-catalyzed oxidative damage through the increase of free iron binding and storage.

The cytoplasmic enzyme NQO1 is important for the reduction of reactive quinones and scavenging of superoxide (Dietz et al., 2013). In bovine mammary epithelial cells, the antioxidant effect of resveratrol was due to its free radical scavenging activity assessed though an increase in the mRNA abundance of $N Q O 1$ (Jin et al., 2016a). Thus, the observed upregulation of NQO1 abundance in response to enhanced methionine supply is suggestive that the antioxidant potential of methionine is partly related to an increase in the cellular capacity to reduce oxidative substances and scavenge free radicals.

\section{NFE2L2 Regulated Pathways}

The transcription factor NFE2L2 belongs to the leucine zipper-type family and binds to antioxidant response elements located in the regulatory regions of many antioxidant genes (Suzuki and Yamamoto, 2015). The current model of NFE2L2 activation takes into account the negative repressor complex formed by KEAP1 and CUL3 (Canning et al., 2015). Alternate mechanisms of NFE2L2 regulation include phosphorylation of NFE2L2 by kinases and interaction with other proteins such as NFKBI and RXRA. The NFE2L2 is activated under several conditions including oxidative stress and specific oxidant compounds. For instance, NFE2L2 activity is stimulated by inflammation (Bryan et al., 2013) and the production of ROM stimulates the release of NFE2L2 from KEAP1, leading to nuclear translocation and activation of the antioxidant response elements in antioxidant target genes (Ho et al., 2005). In addition, antioxidants such as carotenoids and taurine chloramine also can stimulate the activation of the NFE2L2 pathway (Kim et al., 2010; Inoue et al., 2017). A recent study in nonruminants reported that methionine supplementation downregulated KEAP1 mRNA abundance and increased NFE2L2, resulting in improved immune function (Pan et al., 2016). Thus, the upregulation of NFE2L2 and downregulation of KEAP1 abundance in cows with greater methionine supply suggests that it may regulate transcription of the KEAP1/NFE2L2 pathway in mammary tissue.

Mitogen-activated protein kinases (MAPK) are a family of highly related kinases that are composed of extracellular signal-regulated protein kinases, c-jun N-terminal kinases, and p38 kinases. Although, to our knowledge, no data are available on the effect of methionine on the phosphorylation of NFE2L2 protein, the markedly greater ratio of p-NFE2L2/NFE2L2 and upregulation of MAPK14 abundance with methionine suggests a potential role for methionine in the control of NFE2L2 phosphorylation status in mammary tissue. Thus, methionine could potentially exert a posttranslational level of control on phosphorylation of total NFE2L2 protein. Serine phosphorylation of NFE2L2 can occur via MAPK (Sun et al., 2009), PKC (Bloom and Jaiswal, 2003), and ATM serine/threonine kinase (Ma et al., 2017). It is unclear if these kinases regulate NFE2L2 through direct or indirect phosphorylation, but phosphorylation of NFE2L2 in response to oxidative stress promotes its translocation into the nucleus and upregulates transcription of target genes (Huang et al., 2000, 2015). Thus, a central mechanism for the antioxidant potential of methionine in mammary tissue during the periparturient period could occur via phosphorylated NFE2L2 and the upregulation of downstream antioxidant gene abundance.

The regulation of transcription of NFKB and NFE2L2 is affected by redox balance, including protein-protein interactions that control the transcription of downstream target genes (Wakabayashi et al., 2010). In a rat hepatocarcinogenesis model, greater concentration of S-adenosylmethionine abolished the activation of NFKB1 (Garcia-Roman et al., 2008). Thus, the reason for the upregulation of NFKB1 mRNA abundance with enhanced methionine supply is not readily apparent. It could be possible that differences in the flux through the 1-carbon cycle between organs and mammalian species dictates how much S-adenosylmethionine might be available for methylation reactions versus S-adenosylhomocysteine and homocysteine synthesis followed by transsulfuration. In addition, considering that the interaction between NFE2L2 and the NFKB1 pathway operate mainly through posttranscriptional mechanisms (Wardyn et al., 2015), it is possible that changes in NFKB1 abundance do not elicit functional outcomes.

\section{CONCLUSIONS}

Enhancing the supply of methionine during the periparturient period led to greater phosphorylation of the antioxidant transcription regulator NFE2L2 along 
with a reduction in protein abundance of its negative regulator KEAP1 in mammary tissue. As a result, the abundance of the antioxidant protein HMOX1 and various target genes (GPX1, GCLC, GCLM, GSR, $M E 1, F T H 1$, and FECH) under the control of NFE2L2 was upregulated. Although further studies with greater number of cows and additional measurements of lipid peroxidation products at other time points are needed for a better mechanistic understanding, the data suggest the existence of posttranslational and transcriptional mechanisms in mammary tissue during early lactation that likely modulate the antioxidant effect of methionine.

\section{ACKNOWLEDGMENTS}

L. Han received a China Scholarship Council (Beijing) postdoctoral fellowship to train at the University of Illinois (Urbana). Fernanda Batistel was supported by a $\mathrm{PhD}$ fellowship from Coordenação de Aperfeiçoamento de Pessoal de Nível Superior (CAPES, Brazilian Ministry of Education, Brasília, Brazil) and by Hatch funds under project ILLU-538-914, National Institute of Food and Agriculture (Washington, DC). Y. Ma received a China Scholarship Council (Beijing) postdoctoral fellowship to train at the University of Illinois (Urbana). A. S. M. Alharthi is a recipient of a fellowship from King Saud University to perform his $\mathrm{PhD}$ studies at the University of Illinois (Urbana). We thank Perdue AgriBusiness (Salisbury, MD) for the donation of ProVAAl AADvantage during the course of the experiment.

\section{REFERENCES}

AOAC International. 1995. Official Methods of Analysis. Page 17th ed. AOAC International, Arlington, VA.

Batistel, F., J. M. Arroyo, A. Bellingeri, L. Wang, B. Saremi, C. Parys, E. Trevisi, F. C. Cardoso, and J. J. Loor. 2017. Ethyl-cellulose rumen-protected methionine enhances performance during the periparturient period and early lactation in Holstein dairy cows. J. Dairy Sci. 100:7455-7467.

Batistel, F., J. M. Arroyo, C. I. M. Garces, E. Trevisi, C. Parys, M. A. Ballou, F. C. Cardoso, and J. J. Loor. 2018. Ethyl-cellulose rumen-protected methionine alleviates inflammation and oxidative stress and improves neutrophil function during the periparturient period and early lactation in Holstein dairy cows. J. Dairy Sci.101:480-490.

Benzie, I. F., and J. J. Strain. 1996. The ferric reducing ability of plasma (FRAP) as a measure of "antioxidant power": The FRAP assay. Anal. Biochem. 239:70-76.

Berndt, C., C. H. Lillig, and A. Holmgren. 2007. Thiol-based mechanisms of the thioredoxin and glutaredoxin systems: Implications for diseases in the cardiovascular system. Am. J. Physiol. Heart Circ. Physiol. 292:H1227-H1236.

Bionaz, M., and J. J. Loor. 2007. Identification of reference genes for quantitative real-time PCR in the bovine mammary gland during the lactation cycle. Physiol. Genomics 29:312-319.

Bloom, D. A., and A. K. Jaiswal. 2003. Phosphorylation of Nrf2 at Ser40 by protein kinase $\mathrm{C}$ in response to antioxidants leads to the release of Nrf2 from INrf2, but is not required for Nrf2 stabilization/accumulation in the nucleus and transcriptional activation of antioxidant response element-mediated $\mathrm{NAD}(\mathrm{P}) \mathrm{H}$ :quinone oxidoreductase-1 gene expression. J. Biol. Chem. 278:44675-44682.

Bryan, H. K., A. Olayanju, C. E. Goldring, and B. K. Park. 2013. The Nrf2 cell defence pathway: Keap1-dependent and -independent mechanisms of regulation. Biochem. Pharmacol. 85:705-717.

Canning, P., F. J. Sorrell, and A. N. Bullock. 2015. Structural basis of Keap1 interactions with Nrf2. Free Radic. Biol. Med. 88(Pt B):101-107.

Chen, Z. H., G. A. Broderick, N. D. Luchini, B. K. Sloan, and E. Devillard. 2011. Effect of feeding different sources of rumen-protected methionine on milk production and N-utilization in lactating dairy cows. J. Dairy Sci. 94:1978-1988.

Chorley, B. N., M. R. Campbell, X. Wang, M. Karaca, D. Sambandan, F. Bangura, P. Xue, J. Pi, S. R. Kleeberger, and D. A. Bell. 2012. Identification of novel NRF2-regulated genes by ChIP-Seq: Influence on retinoid X receptor alpha. Nucleic Acids Res. 40:74167429 .

Dietz, B. M., G. K. Hagos, J. N. Eskra, G. T. Wijewickrama, J. R. Anderson, D. Nikolic, J. Guo, B. Wright, S. N. Chen, G. F. Pauli, R. B. van Breemen, and J. L. Bolton. 2013. Differential regulation of detoxification enzymes in hepatic and mammary tissue by hops (Humulus lupulus) in vitro and in vivo. Mol. Nutr. Food Res. $57: 1055-1066$

Drackley, J. K. 1999. ADSA Foundation Scholar Award. Biology of dairy cows during the transition period: The final frontier? J. Dairy Sci. 82:2259-2273.

Erdmann, K., N. Grosser, and H. Schroder. 2005. L-methionine reduces oxidant stress in endothelial cells: Role of heme oxygenase-1, ferritin, and nitric oxide. AAPS J. 7:E195-E200.

Garcia-Roman, R., D. Salazar-Gonzalez, S. Rosas, J. Arellanes-Robledo, O. Beltran-Ramirez, S. Fattel-Fazenda, and S. Villa-Trevino. 2008. The differential NF-kB modulation by S-adenosyl-L-methionine, N-acetylcysteine and quercetin on the promotion stage of chemical hepatocarcinogenesis. Free Radic. Res. 42:331-343.

Gozzelino, R., and M. P. Soares. 2014. Coupling heme and iron metabolism via ferritin H chain. Antioxid. Redox Signal. 20:1754-1769.

Han, Z. Y., T. Mu, and Z. Yang. 2015. Methionine protects against hyperthermia-induced cell injury in cultured bovine mammary epithelial cells. Cell Stress Chaperones 20:109-120.

Ho, H. K., C. C. White, C. Fernandez, N. Fausto, T. J. Kavanagh, S. D. Nelson, and S. A. Bruschi. 2005. Nrf2 activation involves an oxidative-stress independent pathway in tetrafluoroethylcysteineinduced cytotoxicity. Toxicol. Sci. 86:354-364.

Huang, H. C., T. Nguyen, and C. B. Pickett. 2000. Regulation of the antioxidant response element by protein kinase C-mediated phosphorylation of NF-E2-related factor 2. Proc. Natl. Acad. Sci. USA 97:12475-12480.

Huang, Y., W. Li, Z. Y. Su, and A. N. Kong. 2015. The complexity of the Nrf2 pathway: Beyond the antioxidant response. J. Nutr. Biochem. 26:1401-1413.

Inoue, Y., M. Shimazawa, R. Nagano, Y. Kuse, K. Takahashi, K. Tsuruma, M. Hayashi, T. Ishibashi, T. Maoka, and H. Hara. 2017. Astaxanthin analogs, adonixanthin and lycopene, activate Nrf2 to prevent light-induced photoreceptor degeneration. J. Pharmacol. Sci. 134:147-157.

Jansova, H., M. Machacek, Q. Wang, P. Haskova, A. Jirkovska, E. Potuckova, F. Kielar, K. J. Franz, and T. Simunek. 2014. Comparison of various iron chelators and prochelators as protective agents against cardiomyocyte oxidative injury. Free Radic. Biol. Med. 74:210-221.

Jin, X., K. Wang, H. Liu, F. Hu, F. Zhao, and J. Liu. 2016a. Protection of bovine mammary epithelial cells from hydrogen peroxideinduced oxidative cell damage by resveratrol. Oxid. Med. Cell. Longev. 2016:2572175.

Jin, X. L., K. Wang, L. Liu, H. Y. Liu, F. Q. Zhao, and J. X. Liu. 2016b. Nuclear factor-like factor 2-antioxidant response element signaling activation by tert-butylhydroquinone attenuates acute heat stress in bovine mammary epithelial cells. J. Dairy Sci. 99:9094-9103. 
Kim, C., J. S. Jang, M. R. Cho, S. R. Agarawal, and Y. N. Cha. 2010. Taurine chloramine induces heme oxygenase- 1 expression via Nrf2 activation in murine macrophages. Int. Immunopharmacol. 10:440-446.

Lu, S. C. 2013. Glutathione synthesis. Biochim. Biophys. Acta 1830:3143-3153.

Ma, Y. F., Z. H. Wu, M. Gao, and J. J. Loor. 2017. Nuclear factor, erythroid 2 like 2 (Nrf2) activation through the action of ATM serine/threonine kinase is essential to counteract oxidative stress in bovine mammary epithelial cells. J. Dairy Sci. 101:5317-5328.

Martinov, M. V., V. M. Vitvitsky, R. Banerjee, and F. I. Ataullakhanov. 2010. The logic of the hepatic methionine metabolic cycle. Biochim. Biophys. Acta 1804:89-96.

Mu, T., G. H. Kong, Z. Y. Han, and H. X. Li. 2014. Cytoprotection of methionine on hyperthermia-induced damage in bovine mammary epithelial cells. Cell Biol. Int. 38:971-976.

Naeem, A., J. K. Drackley, J. Stamey, and J. J. Loor. 2012. Role of metabolic and cellular proliferation genes in ruminal development in response to enhanced plane of nutrition in neonatal Holstein calves. J. Dairy Sci. 95:1807-1820. https://doi.org/10.3168/jds .2011-4709

Niture, S. K., and A. K. Jaiswal. 2012. Nrf2 protein up-regulates antiapoptotic protein Bcl-2 and prevents cellular apoptosis. J. Biol. Chem. 287:9873-9886.

NRC. 2001. Nutrient Requirements of Dairy Cattle. 7th rev. ed. National Academy Press, Washington, DC.

Ordway, R. S., S. E. Boucher, N. L. Whitehouse, C. G. Schwab, and B. K. Sloan. 2009. Effects of providing two forms of supplemental methionine to periparturient Holstein dairy cows on feed intake and lactational performance. J. Dairy Sci. 92:5154-5166.

Osorio, J. S., P. Ji, J. K. Drackley, D. Luchini, and J. J. Loor. 2013 Supplemental Smartamine M or MetaSmart during the transition period benefits postpartal cow performance and blood neutrophil function. J. Dairy Sci. 96:6248-6263.

Osorio, J. S., P. Ji, J. K. Drackley, D. Luchini, and J. J. Loor. 2014a. Smartamine $\mathrm{M}$ and MetaSmart supplementation during the peripartal period alter hepatic expression of gene networks in 1-carbon metabolism, inflammation, oxidative stress, and the growth hormone-insulin-like growth factor 1 axis pathways. J. Dairy Sci. 97:7451-7464.

Osorio, J. S., E. Trevisi, P. Ji, J. K. Drackley, D. Luchini, G. Bertoni, and J. J. Loor. 2014b. Biomarkers of inflammation, metabolism, and oxidative stress in blood, liver, and milk reveal a better immunometabolic status in peripartal cows supplemented with Smartamine M or MetaSmart. J. Dairy Sci. 97:7437-7450.

Pan, F. Y., L. Feng, W. D. Jiang, J. Jiang, P. Wu, S. Y. Kuang, L. Tang, W. N. Tang, Y. A. Zhang, X. Q. Zhou, and Y. Liu. 2016 Methionine hydroxy analogue enhanced fish immunity via modulation of NF-kappaB, TOR, MLCK, MAPKs and Nrf2 signaling in young grass carp (Ctenopharyngodon idella). Fish Shellfish Immunol. 56:208-228.

Ratledge, C. 2014. The role of malic enzyme as the provider of NADPH in oleaginous microorganisms: A reappraisal and unsolved problems. Biotechnol. Lett. 36:1557-1568.

Roche, J. R., A. W. Bell, T. R. Overton, and J. J. Loor. 2013. Nutritional management of the transition cow in the 21st centuryA paradigm shift in thinking. Anim. Prod. Sci. 53:1000-1023. https://doi.org/10.1071/AN12293.
Schogor, A. L., M. F. Palin, G. T. Santos, C. Benchaar, P. Lacasse, and H. V. Petit. 2013. Mammary gene expression and activity of antioxidant enzymes and oxidative indicators in the blood, milk, mammary tissue and ruminal fluid of dairy cows fed flax meal. Br. J. Nutr. 110:1743-1750.

Schwab, C. G., and G. A. Broderick. 2017. A 100-Year Review: Protein and amino acid nutrition in dairy cows. J. Dairy Sci. 100:1009410112.

Sordillo, L. M., and S. L. Aitken. 2009. Impact of oxidative stress on the health and immune function of dairy cattle. Vet. Immunol. Immunopathol. 128:104-109

Sun, Z., Z. Huang, and D. D. Zhang. 2009. Phosphorylation of Nrf2 at multiple sites by MAP kinases has a limited contribution in modulating the Nrf2-dependent antioxidant response. PLoS One 4:e6588.

Suzuki, T., and M. Yamamoto. 2015. Molecular basis of the Keap1Nrf2 system. Free Radic. Biol. Med. 88(Pt B):93-100.

Wakabayashi, N., S. L. Slocum, J. J. Skoko, S. Shin, and T. W. Kensler. 2010. When NRF2 talks, who's listening? Antioxid. Redox Signal. 13:1649-1663.

Wardyn, J. D., A. H. Ponsford, and C. M. Sanderson. 2015. Dissecting molecular cross-talk between Nrf2 and NF-kappaB response pathways. Biochem. Soc. Trans. 43:621-626.

Xu, T., F. C. Cardoso, A. Pineda, E. Trevisi, X. Shen, F. Rosa, J. S Osorio, and J. J. Loor. 2017. Grain challenge affects systemic and hepatic molecular biomarkers of inflammation, stress, and metabolic responses to a greater extent in Holstein than Jersey cows. J. Dairy Sci. 100:9153-9162.

Zhou, Z., O. Bulgari, M. Vailati-Riboni, E. Trevisi, M. A. Ballou, F. C. Cardoso, D. N. Luchini, and J. J. Loor. 2016a. Rumen-protected methionine compared with rumen-protected choline improves immunometabolic status in dairy cows during the peripartal period. J. Dairy Sci. 99:8956-8969.

Zhou, Z., T. A. Garrow, X. Dong, D. N. Luchini, and J. J. Loor. 2017. Hepatic activity and transcription of betaine-homocysteine methyltransferase, methionine synthase, and cystathionine synthase in periparturient dairy cows are altered to different extents by supply of methionine and choline. J. Nutr. 147:11-19.

Zhou, Z., M. Vailati-Riboni, D. N. Luchini, and J. J. Loor. 2016b. Methionine and choline supply during the periparturient period alter plasma amino acid and one-carbon metabolism profiles to various extents: Potential role in hepatic metabolism and antioxidant status. Nutrients 9. https://doi.org/10.3390/nu9010010.

Zhou, Z., M. Vailati-Riboni, E. Trevisi, J. K. Drackley, D. N. Luchini, and J. J. Loor. 2016c. Better postpartal performance in dairy cows supplemented with rumen-protected methionine compared with choline during the peripartal period. J. Dairy Sci. 99:8716-8732.

Zhou, Z., M. Vailati-Riboni, E. Trevisi, J. K. Drackley, D. N. Luchini, and J. J. Loor. 2016d. Better postpartal performance in dairy cows supplemented with rumen-protected methionine compared with choline during the peripartal period. J. Dairy Sci. 99:8716-8732.

Zhuang, C., Z. Miao, C. Sheng, and W. Zhang. 2014. Updated research and applications of small molecule inhibitors of Keap1-Nrf2 protein-protein interaction: A review. Curr. Med. Chem. 21:18611870. 